gadolinium-enhanced MRI is viewed as critical for the wellbeing of the mother, this would presumably outweigh any potential risks to the fetus and the test should be performed after obtaining informed consent.

Joel G. Ray, MD, MSc, FRCPC

Aditya Bharatha, MD, FRCPC

Walter J. Montanera, MD, FRCPC

Author Affiliations: Department of Medicine, St Michael's Hospital, Toronto, Ontario, Canada (Ray); Department of Medical Imaging, St Michael's Hospital, Toronto, Ontario, Canada (Bharatha, Montanera).

Corresponding Author: Joel G. Ray, MD, MSc, FRCPC, Department of Medicine, St Michael's Hospital, 30 Bond St, Toronto, ON M5B 1W8, Canada (rayj@smh.ca)

Conflict of Interest Disclosures: The authors have completed and submitted the ICMJE Form for Disclosure of Potential Conflicts of Interest. Dr Ray reported support by an Applied Research Chair in Reproductive and Child Health Services and Policy Research award from the Canadian Institutes of Health Research. No other disclosures were reported.

1. Chen MM, Coakley FV, Kaimal A, Laros RK Jr. Guidelines for computed tomography and magnetic resonance imaging use during pregnancy and lactation. Obstet Gynecol. 2008;112(2 Pt 1):333-340.

2. Morita S, Masukawa A, Suzuki K, Hirata M, Kojima S, Ueno E. Unenhanced MR angiography: techniques and clinical applications in patients with chronic kidney disease. Radiographics. 2011;31(2):E13-E33.

\section{Shared Decision Making Regarding Aspirin in Primary Prevention of Cardiovascular Disease}

To the Editor The Viewpoint by Dr Mora and colleagues ${ }^{1}$ focused on weighing the benefit of aspirin to reduce atherosclerotic cardiovascular disease (ASCVD) events against the risk of aspirin to increase bleeding events. We appreciate the emphasis on assessing absolute (rather than relative) risks and benefits. However, we take exception to the authors' decision support algorithm that directly converts these absolute risks and benefits into a decision by calculating if the sum of benefits is higher or lower than the sum of risks. At various points in the article and in the supplemental algorithm, the authors stated that if the number needed to treat (NNT) is lower than the number needed to harm (NNH), then the recommendation would be to advise aspirin. Conversely, if the NNT is higher than the $\mathrm{NNH}$, then the recommendation would be to avoid aspirin. We recognize that all recommendations have limits and will be inappropriate in certain situations. However, the algorithm makes assumptions that may be invalid in many situations of shared decision making.

Shared decision making requires that clinicians base recommendations on the patient's values. ${ }^{2}$ As such, the weighing of NNT vs NNH suggested by Mora and colleagues has problems. First, it assumes that the patient would place equal value on the 2 outcomes; ie, that the patient would judge an ASCVD event to be equal to a bleeding event. Although this may be true for certain people, the assumption ignores the fact that some might place more value on avoiding an ASCVD, and others may place more value on avoiding a bleeding event. ${ }^{3}$ In fact, research suggests that patients may be less averse than clinicians to bleeding as an adverse effect of stroke prophylaxis with aspirin. ${ }^{4}$

Second, even if patients placed equal value on the 2 outcomes, the algorithm implies that patients would also place equal value on gains and losses. A basic tenet of research in behavioral psychology suggests that people place less value on reaping gains than on avoiding losses. ${ }^{5}$ Thus, even if the patient valued the 2 outcomes equally, and the NNT were lower than the NNH, it may still be appropriate for a clinician practicing shared decision making to recommend that the patient avoid aspirin.

\section{Steven D. Stovitz, MD, MS \\ David J. Satin, MD \\ Ian Shrier, MD, PhD}

Author Affiliations: Department of Family Medicine and Community Health University of Minnesota, Minneapolis (Stovitz, Satin); Centre for Clinical Epidemiology, Lady Davis Institute, Montreal, Quebec, Canada (Shrier).

Corresponding Author: Steven D. Stovitz, MD, MS, University of Minnesota, Department of Family Medicine and Community Health, 420 Delaware St SE, MMC 381, Minneapolis, MN 55455 (stovitz@umn.edu).

Conflict of Interest Disclosures: The authors have completed and submitted the ICMJE Form for Disclosure of Potential Conflicts of Interest and none were reported.

1. Mora S, Ames JM, Manson JE. Low-dose aspirin in the primary prevention of cardiovascular disease: shared decision making in clinical practice. JAMA. 2016; 316(7):709-710.

2. Kon AA. The shared decision-making continuum. JAMA. 2010;304(8):903904.

3. Guyatt GH, Haynes RB, Jaeschke RZ, et al; Evidence-Based Medicine Working Group. Users' Guides to the Medical Literature: XXV-Evidence-based medicine: principles for applying the users' guides to patient care. JAMA. 2000;284(10): $1290-1296$

4. Devereaux PJ, Anderson DR, Gardner MJ, et al. Differences between perspectives of physicians and patients on anticoagulation in patients with atrial fibrillation: observational study. BMJ. 2001;323(7323):1218-1222.

5. Kahneman D, Tversky A. Prospect theory: an analysis of decision under risk. Econometrica. 1979;47(2):263-292. doi:10.2307/1914185

In Reply Clinical decision making regarding the appropriate use of aspirin for the primary prevention of ASCVD events is a complex process that requires assessment of the benefits and risks for the individual patient. ${ }^{1}$ Critically important elements of the process include evaluation of the patient's absolute risk of ASCVD (the primary determinant of potential benefit, calculated as the NNT) and the patient's absolute risk of bleeding (the primary determinant of potential risk, calculated as the $\mathrm{NNH})$. Making these parallel assessments within the work flow of routine clinical care is difficult, and guidance on how to do so and how to use this information to identify appropriate candidates for treatment has not previously been available. We developed a clinical decision-support tool and mobile app (Aspirin-Guide) to help clinicians with this dual assessment for individual patients and to support evidence-based decision making for the use of aspirin in primary prevention in the context of what matters to the patient.

We agree with Dr Stovitz and colleagues that patients can legitimately differ in the weights they assign to the benefits and harms of aspirin therapy for primary prevention, despite the absence of consensus among researchers and developers of clinical guidelines on these comparative weights. The aspirin clinical decision-support tool is not limited to calculating and comparing the NNT and NNH but also incorporates the patient's willingness to take daily aspirin on a long-term basis 
for prevention. It is not intended to produce the correct or only decision but to facilitate the shared decision-making conversation by providing the tailored estimates of risk and benefit for the individual patient (instead of generalized population estimates). In the process of using the decision-support tool, the clinician and patient engage in a discussion that explores and compares the risk vs benefit information, elicits the patient's values and preferences, and makes the shared decision. ${ }^{2-4}$ Hence, the final patient-centered decision is made by the patient together with the clinician, based not only on the patient's risks and benefits, but incorporating the patient's preferences, values, concerns, and goals of care.

\section{Samia Mora, MD, MHS}

JoAnn E. Manson, MD, DrPH

Author Affiliations: Department of Medicine, Brigham and Women's Hospital, Boston, Massachusetts.

Corresponding Author: JoAnn E. Manson, MD, DrPH, Brigham and Women's Hospital, Harvard Medical School, 900 Commonwealth Ave, Third Floor, Boston, MA 02215 (jmanson@rics.bwh.harvard.edu).

Conflict of Interest Disclosures: The authors have completed and submitted the ICMJE Form for Disclosure of Potential Conflicts of Interest. Dr Mora reported receipt of research support from Atherotech Diagnostics and the National Heart, Lung, and Blood Institute; serving as a consultant to Amgen, Quest Diagnostics, Lilly, Pfizer, and Cerenis Therapeutics; and having a patent application on the use of an NMR spectroscopy biomarker for predicting risk of colorectal cancer. No other disclosures were reported.

1. Mora S, Manson JE. Aspirin for primary prevention of atherosclerotic cardiovascular disease: advances in diagnosis and treatment. JAMA Intern Med. 2016;176(8):1195-1204.

2. Fried TR, Tinetti ME, Towle V, O'Leary JR, lannone L. Effects of benefits and harms on older persons' willingness to take medication for primary cardiovascular prevention. Arch Intern Med. 2011;171(10):923-928.

3. Seaburg L, Hess EP, Coylewright M, Ting HH, McLeod CJ, Montori VM. Shared decision making in atrial fibrillation: where we are and where we should be going. Circulation. 2014;129(6):704-710.

4. Fried TR. Shared decision making-finding the sweet spot. N Engl J Med. 2016; 374(2):104-106.

\section{CORRECTION}

Errors in Equation and Modeling Parameter: In the Original Investigation entitled "Association Between Gun Law Reforms and Intentional Firearm Deaths in Australia, 1979-2013," published in the July 19, 2016, issue of JAMA, ${ }^{1} 2$ small typographical errors occurred. In the Methods section, in the equation for Model c, the second operator should be a plus sign (not an equals sign). Also in the Methods section, a paragraph describing the models should use the expression $e^{\beta 32}$ as such: "The 3 models are related because the model is parameterized, $\beta_{32}=\beta_{11}-\beta_{10}$. and therefore, $e^{\beta 32}$ estimates the ratio of annual trend...." The article was corrected online.

1. Chapman $S$, Alpers $P$, Jones $M$. Association between gun law reforms and intentional firearm deaths in Australia, 1979-2013. JAMA. 2016;316(3):291-299.

\section{Guidelines for Letters}

Letters discussing a recent JAMA article should be submitted within 4 weeks of the article's publication in print. Letters received after 4 weeks will rarely be considered. Letters should not exceed 400 words of text and 5 references and may have no more than 3 authors. Letters reporting original research should not exceed 600 words of text and 6 references and may have no more than 7 authors. They may include up to 2 tables or figures but online supplementary material is not allowed. All letters should include a word count. Letters must not duplicate other material published or submitted for publication. Letters not meeting these specifications are generally not considered. Letters being considered for publication ordinarily will be sent to the authors of the JAMA article, who will be given the opportunity to reply. Letters will be published at the discretion of the editors and are subject to abridgement and editing. Further instructions can be found at http://jama.com/public /InstructionsForAuthors.aspx. A signed statement for authorship criteria and responsibility, financial disclosure, copyright transfer, and acknowledgment and the ICMJE Form for Disclosure of Potential Conflicts of Interest are required before publication. Letters should be submitted via the JAMA online submission and review system at http: //manuscripts.jama.com. For technical assistance, please contact jama-letters@jamanetwork.org.

Section Editor: Jody W. Zylke, MD, Deputy Editor. 